Received Date : 05-Apr-2016

Revised Date : 24-Jun-2016

Accepted Date : 15-Jul-2016

Article type : Original Article

Corresponding Author E-Mail ID: c.robins@ucl.ac.uk

\title{
Who Assesses the Assessors? sustainability and assessment in art and design education
}

Claire Robins

\begin{abstract}
:
This paper draws on recent research from the Pre-Degree Summative Assessment in Art Design and Media Study, conducted at UCL Institute of Education, which found that pre-degree art and design qualifications at levels 3 and 4 vary greatly in their appropriateness as a preparation for degree level study in art subjects. Central to the paper are findings concerning external assessment processes and assessor selection and training. The research was commissioned by the awarding body of University of the Arts London in response to the then imminent Department for Education (DFE) directives for additional external assessment in all level 3 and 4 vocational pre-degree programmes. Our research revealed the negative consequences of assessment becoming a bureaucratic process of measuring what is most easily measurable. In such instances it can become a task that is devoid of 'expert' knowledge and opinion. As the research demonstrates, the consequences for art education are serious. The title is appropriated from Bourdieu's 1993 sociological examination 'But Who Created the "Creators"?' which casts a critical eye on the broader social landscape in which art and artists are
\end{abstract}


produced and imbricated into the wider cultural order. To ask, who assesses the assessors? is of course to ask a different kind of question, but never-the-less it is one which deserves to be opened out to scrutiny beyond the specificity of individual qualifications. This paper's contribution argues for a more sustainable and radically transparent assessment regime in which professional expertise can be shared across the UK's secondary, further and higher education continuum.

Keywords: assessment, transition, university entry, selection processes, moderation, exam boards, pre-degree qualifications, A-level, Foundation Diploma, BA

Background to the research

The research informing this paper was conducted by myself as principal investigator, Gwyneth Hughes, Reader in Higher Education with expertise in assessment, and Miriam Craik Horan who was employed as a researcher.

The purpose was to determine the impact of different processes for summative assessment in pre-degree art subject qualifications and their fitness for purpose. Qualitative and quantitative research methods were employed commencing with an online questionnaire containing a range of ranked and open questions which was sent to 433 programme leaders of pre-degree qualifications in art subjects and achieved a total response rate of $\mathbf{4 2}$ per cent (182 respondents out of the 433 invited to participate). Of the respondents ( 84 per cent) had been teaching for more than 10 years, positioning them favourably to comment on the changes to assessment procedures that have been experienced in the last decade. We also achieved returns from a high proportion ( 73 per cent) of respondents who had experience working across different sectors, levels and qualifications. More than half (57 per cent) had experience of teaching across three 
sectors (secondary, further education and higher education). Again this provided a good balance of views when respondents were asked to reflect on the assessment processes involved in the range of pre-degree qualifications.

Interviews and focus groups were also employed for the richer communicative context that they provide. All were digitally recorded and professionally transcribed. The coding frame was based on the semi-structured questions but also developed in response to emergent themes in order to reflect the capacity of focus groups to generate new ideas and directions. In this paper I have drawn particularly on the focus group data from a total of 18 participants which allowed us to: a) capture more detail from the original questionnaire respondents working in a range of contexts from FE colleges, art colleges and universities; b) obtain the views of national and international experts in the field of arts assessment; c) gather opinions of BA programme leaders; d) include the opinions of the National Society for Art and Design Education and other professional bodies and those with close links to the creative industries; and, e) elicit views from Alevel teachers and moderators in response to the frequent discussion of this pre-degree qualification in focus groups 1-3.

Data from questionnaire, focus groups and interviews is represented in this paper with the following features:

'RN' Respondent number (from 1-182)

- 'IN' Interviewee Number, the identifier applied to each focus group participant (from 1-18)

- 'FG' refers to the focus groups (from 1-4). 
Preamble

On a bright, crisp February morning I cross Woburn Square in central London leaving the brutalist concrete building of UCL's Institute of Education for the Warburg Institute a few hundred yards away. This is home to the Research Centre for UCL's Slade School of Fine Arts and for a week it is also the site where portfolio selection for the Slade's next undergraduate Fine Art intake takes place. This is the first stage of the selection process in which around 1,500 national and international 'hopefuls' compete for just 40 to 50 places.

The Slade may not be representative of the different selection approaches taken by BA courses in art subjects in the UK but it can never-the-less provide a useful starting point for some thoughts on role that examinations, awarding bodies and university selection processes have to play in achieving sustainability in art education.

As I arrive, two panels each consisting of three experienced members of Slade academic staff are already at work on the selection task. It is noteworthy that a process of discursive group decision-making is employed, regardless that each selector is an internationally respected artist with secure professional knowledge. In art subjects, where subjectivity inevitably plays a role, consensus becomes additionally important in evaluative tasks. As Susan Orr writes, 'We flood our assessment process with staff. [...] The fact that group approaches to marking have remained a central tenet of art and design assessment in the face of massification and the intensification of lecturers' workloads underlines its importance' (2010). As each group carefully scrutinizes a portfolio of artwork the applicant's UCAS statementi, including their current place of study, is read aloud to provide some contextualization of prior learning. 
Applicants can find advice on what the selectors are looking for on-line, 'self-initiated work' is specified with the caveat that this does not mean 'course / project work.' As our research revealed, demonstrating independent learning leading to student-led artwork will not be a central priority for some pre-degree qualifications. Therefore, meeting the selector's specifications will will be easier to achieve for some applicants than for others. Many applicants recognize the need to take an additional course, typically the Foundation Diploma, in preparation for degree study in Fine Art, but as the Slade's (2016) web information for applicants states: 'it is not an entrance requirement.'

'These are all Foundation' someone advises (indicating that the applicants have all come from Foundation Diploma courses), 'look, over here they have some A-level in the other group.'

Susan Collins, Slade Director, is keen to stress that there are excellent students who have come direct from A-level and it is important to acknowledge the pockets of inspirational practice, against the odds, in number of school art departments throughout the UK. However, those whose portfolios we see confirm the views of teachers and lecturers surveyed in our research. They demonstrate almost perfectly why A-level art so often fairs badly in adequately preparing students for studying art subjects at university.

With each annotated page of A-level work that we see, I am cannot stop myself from conjuring a mental image of a 2015 Pearson's examination board handbook for moderators, that has been haunting me. It carries the words 'strictly confidential' on its cover and here, on this auspicious February morning its 'secret contents' seem to have 
cast a negative influence on the future aspirations of a number of young people. The work in these students' portfolios uniformly reflects the exemplars in the handbook, and as such it is not what is being sought.

Students are much less likely to proceed from A-level to undergraduate programmes in art subjects than in other subject areas. Perhaps surprisingly (to those not familiar with art education) achievement of the highest grade at A-level also does not necessarily correlate with the requirements for study at degree level, as one of our interviewee's comment reveals, 'We had one boy who tried to go, this year, straight to a degree programme, but he failed, he applied to all kinds of places actually and didn't get in. He had an $\mathrm{A}^{*}$ [grade awarded for A level qualification]' (IN16, FG4).

This longstanding situation has registered as a cause for concern but clearly has not generated enough consternation to initiate change, and the discrepancy remains. Recommendations that to be fit for purpose post-compulsory grading systems should reflect and reveal the candidates' strengths, abilities, and motivations to support transition to suitable progression routes (Stecher, 2010: 34-6), seem not to apply here, as students will typically need to complete a Foundation Diploma in order to develop the study skills and relevant knowledge required for undergraduate study. Candidates for degree courses in art subjects continue to be selected primarily by their 'portfolio' therefore the selectors are very often looking at the very same artwork that will be graded for pre-degree qualifications. This effectively means that there may be two groups of art and design educators considering the merits of the same work but often making quite different evaluative pronouncements. Our research found that such occurrences of disparate judgment are particularly common between A-level examiners and higher education selectors. In part this may be attributable to the fact that school's 
final examination structures are looking for a form of closure in student's artwork, whereas selectors in higher education will be looking for emergent signs of potential. However, there are other factors that are increasingly affecting the experiences of students studying art in mainstream UK secondary schools, which have to do with the processes and practices of assessment.

The general lack of continuity in some progression routes to higher education is particularly worrying in the current economic climate where the necessity of an additional year of study, such as the Foundation Diploma, has a prohibitory effect. It is noteworthy too, that in an increasing drive for standardized admission procedures a number of BA providers are accepting students straight from A-level programmes. There is not space in this paper to explore this trend but the research interviews confirmed that a number of design subjects, such as visual communication, architecture, graphic and product design, appear to favour direct application from A-level.

An issue of transparency

To return to Edexcel's moderator handbook; this same document was referred to by a teacher who had recently received moderator training, and failed to comprehend why there was a culture of secrecy around this examination board's practices.

One thing to say, I don't know if AQA's the same, but in Edexcel the booklet, it says not to be shown to anyone on the cover, which is absolutely mind boggling, you know what I mean? The examples tell you what level things are but is not to be shared with your art department, for example, you know, it's crazy.

(IN13, FG4)

In both the handbook and the training moderators reported a sense of rightness and measure which precluded consensus or debate. The perception that a moderator's task was to get the grade right only in accordance with the examples given, was shared by 
interviewees. There was also a general recognition of a diminished impetus to encourage learning and teaching that manifests independent or contemporary ways of working. As an interviewee described, 'If A-level is supposed to be a pathway to university the people who run assessment need to be having a conversation with A-level moderators, it's as simple as that, because, in every single one of those examples, [in the handbook] there is no video work, sound work, there is no new media work whatsoever' (IN13, FG4). Although the examples in the booklet are produced by different students, stylistically they look almost identical and follow a formula that has come to be associated with 'school art,' a distinctive genre characterised by Authur Hughes almost 20 years ago as akin to, 'the conceptually unambitious work of a skilful amateur' (Hughes, 1998: 42). Perhaps with the passing of time, even this link to practices outside the school has diminished. Now the work carries the trademarks of preparatory studies, linear development, reference to a predictable selection of artists' work and obligatory but often facile annotation.

Another secondary school art teacher with twelve years' experience as a moderator further explains how the moderator training favours 'standards levelled' examples of very limited approaches to art making, 'The top marks have observational drawing leading up in a very linear way to a final piece that has critical and contextual studies linked with it, and the whole thing nicely meets all the objectives. Uncomplicated' (IN14, FG5).

Art in schools, as Nichols Addison (2001) among many others has pointed out, 'is not for the training of artists, craftspeople and designers' (p. 20). This, of course is true, however to over emphasise the divisions in the way that any subject should be 
experienced and taught in the continuum from school to university can also bring its own problems.

We only have to reflect on the tug of war in the intentions for art in elementary school at the end of the nineteenth century and beginning of the twentieth century to get a feel for unhelpful pendulum swings in the expectations of what students might encounter in the name of art education. If art's initial introduction into the schooling system was predicated on facilitating drawing skills for manual workers it wasn't long before this was ousted by concerns for 'child art' and its revelations for cognitive development stages, that completely detached the experience from the art of the adult world.

For secondary school teachers today the luxury of such debates concerning the rationale for art's place in the school curriculum seem distant and are largely eclipsed by the overwhelming pressure to focus myopically on achieving good examination results. To enable students to excel in examinations is of paramount importance but the question posed by the research is, does examination success command any currency and authenticity in a progressive continuum of learning?

The teachers who took part in the research explained how their examination moderation systems had moved increasingly towards standardisation and norm referencing. External marking of GCEs is referred to as 'moderation' but it differs substantively from the moderation process for Foundation Diploma, Extended Diploma and the vocational BTEC. For art teachers, this visit is rarely perceived as an external moderation of internal grading. Rather, it is frequently experienced as an external 'examination' of their ability to conform to teaching an increasingly prescribed set of student outcomes; to play by the rules. 
A very experienced head of art comments,

I think I've always taught like a Foundation style A-level, and I've had feedback in the last few years that it's not formal enough and that's what worries me. Because also the school I worked at previously, which does have an excellent department, (really experimental and phenomenal work, on a very small budget), they've had their grades put down this year for the first time ever. And I know a few other people that are in the same situation.

(IN15, FG4)

The research also captured comments about the ways in which moderator training for A-level promoted limited understandings of how criteria might be interpreted differently (for example using different media, engaging with design work or digital media) but still attain a comparable grade.

Of all the pre-degree programmes our research examined it was A-level, which had the highest levels of external intervention and assessment and the lowest levels of expectation for student autonomy. It was also conclusively thought to be the least effective qualification for progression to BA. Of the 182 questionnaire respondents only seven per cent endorsed A-Level as a 'good' option for preparing students for further study. As one respondent qualified, 'A-Level is a box ticking exercise that does not teach students to be independent and self-motivated [which are] the skills required to be successful on BA degree creative programmes' (RN, 77).

My visit to the Slade comes close on the heels of a focus group I attended about evaluating the effects of the arts in public health. This event brimmed with positivity until the disappointing content of secondary school art entered the debate; a hospital doctor and a GP were in agreement that their children were genuinely interested in art but detested the school subject. This was not about progression to study art but instead 
reflected a disappointment that their children wanted to drop this 'creative' subject because they found it to be, a) 'unchallenging,' b) 'all about observational drawing,' c) 'and with no relation to other art practices they were interested in.' I had to wearily agree, 'Oh yes,' I said 'but what they do is so measurable.'

Measurement has become the order of the day in the neo-liberal education economy. It is experienced in extremis in the new academy schoolii where the arts struggle to command their social value and where frequent testing, reduced time allocations, and a lack of resources further erodes their relevance.

Despite assessment's complex domain of interrelated divergent processes, in many schools the current emphasis on summative assessment is negating the importance of formative, ipsative, synoptic, diagnostic, peer, and self-assessments. Our research demonstrated very real tensions between assessment of and assessment for learning in art subjects right through the spectrum of pre-degree programmes. The imperative for a culture of external assessment and audit means that the assessment for learning approach tends to be overshadowed by assessment of learning, which places more emphasis on measurements than the impact of assessment on learning (Hughes, 2014).

For art subjects this has had its biggest impact on authenticity and therefore the validity of the forms of assessment that teachers find themselves forced to administer. A passage written by an art teacher and UCL MA student brings some immediate context,

When inspection systems and very reductive forms of assessment become the driving force of educational practice, a kind of corrosion of what one knows to be true sets in and undermines personal integrity. Negotiating this complex situation is puzzling and can be demoralising, as I was reminded quite recently, when forced to undergo the mind-bending exercise of contriving a 'mastery assessment 
in art', which absurdly awarded a higher 'number' for 'drawing using tone' than for 'drawing using line'.

It is the undermining effects of such exercises on authentic forms of assessment that we should pay heed to here. It is clear that educational assessment needs to strike a balance between enabling autonomous learners through authentic learning and assessment, and meeting the irrefutable requirement for an examination system that is regarded as reliable and rigorous. However, as in the case above, assessment ceases to have a developmental function if it is perceived as an arbitrary force that is 'done to' rather than 'negotiated by' teaching professionals. When educational assessment in its diverse forms is replaced by almost Kafkaesqueiii scenarios, then it must be questioned.

As Sociologist Stephen Ball states, 'teachers [in schools] are no longer encouraged to have a rationale for practice, account of themselves in terms of a relationship to the meaningfulness of what they do, but are required to produce measurable and “improving” outputs and performances' (2005: 150).

In art subjects particularly, focusing solely on measurability affects subject pedagogy, often promoting an overreliance on the teaching of content that can most easily and reliably be assessed. The meaningfulness of the curriculum, for both teachers and students, therefore slips towards only the achievement of grades. Measure tips meaning out of balance. In the research it was acknowledged that certain types of artwork would be 'easier to mark' than others, and that a turn towards increasing external assessment would be likely to privilege readily visible and discernable aspects of student work to the detriment of more complex, conceptual, critical and original outcomes. 
Where art education is suffering the ill effects of conforming to a regime of measurability an antidote might be to consider dismeasure, which, as Pascal Gielen (2015) reminds us, has a strong historical links to modern art and the teaching of art subjects. In his paper on the role of play in arts education, Gielen writes of an aspect of arts education that should concern itself with understanding and testing measure rather than blindly following its mandate. His point is connected with the need for students to learn how 'to break and manipulate rules in order to play according to new rules which in turn can be broken.' (Gielen, 2015: 148). Such iterative testing processes still seem fundamental to creative practice and as Gielen suggests the assignment for art teachers that history bestows on them is that 'they must teach this dismeasure' (ibid). For teachers working in schools this has become increasingly difficult.

The research also uncovered another division in the pre-degree awards and awarding bodies concerning those who are 'selected' for the role of verifying and maintaining national standards. In the main lecturers in further and higher education expressed confidence in external moderation viewing the role as one that also contributes to the development of programmes. The Foundation Extended Diploma moderation was characterised as conducted by 'experienced practitioners who apply through the awarding body for those positions, ... so there is obviously a process of selection, selecting the right people, who the awarding bodies confirm can do that role' (IN6, FG2). It was also felt that those moderating needed by necessity to be 'at the top of their game' and that there was 'an onus to keep up to date with things, to research and develop' (IN1, FG1). This contrasted with those views held by A-level art teachers, who expressed a lack of confidence in their moderators and who found the increasingly nondiscursive approach to the moderation visit 'frustrating' and 'not really good enough'. 
There was a perception that many A-level moderators were 'out of touch.' The combined effects of a shortage of relevant up-to date expertise in the moderator workforce and an increased imperative for external verification, appears to be driving what the respondents characterised as 'tick box' assessment approaches. One A-level moderator stated, "it has become increasingly difficult to get "good moderators" because schools won't let them out, they won't absorb the cost' (IN14, FG5). Teachers confirmed the lack of up-to-date experience, 'over the last two years we've had only retired people. Not that there's anything wrong with retired people, but the point is they are at a distance from being in the classroom' (IN15, FG4). Teachers also suggested, more harshly, that these moderators were, 'either inexperienced teachers, needing pin money or people who have retired and don't understand the episteme' (IN10, FG3).

The lack of authenticity in moderation approaches was the cause of much discussion as it was felt to compromise the complexity involved in making professional evaluations about student learning and achievement in arts subjects. Art educators, from BA Foundation Diploma, BTEC and A-level all reinforced the importance of group internal assessment and external verification noting, in line with Orr's findings, that whilst this was time consuming it was also in keeping with the complex nature of making expert judgments in a creative subject. As Smith suggests, 'because assessment so strongly influences student attention, perceptions and behaviours, it ultimately functions not only as a measure of learning [as perhaps it is typically viewed], but also as a shaper of learning' (2013: 204). Our research has suggested assessment also becomes a shaper of teaching.

Conclusion 
An increasingly instrumentalist regime of external assessment was central to the context of the research and our findings demonstrate that unless such externality has appropriate levels of resourcing and professional expertise it will not be fit for purpose. Rather, it can already be seen to be exacerbating the disjunction for art education between schools and universities.

The difference in what was valued in assessments across the spectrum of pre-degree awards was perceived by a number of interviewees as 'troublesome' and was identified as leading to 'unnecessary misunderstanding' for students between different programmes of study. This was felt to be intensified by a lack of opportunity for professional contact and discussion between those working in different sectors, particularly between schools and universities. In the main, lecturers in higher education appeared unaware of the conditions that were driving many schoolteachers to take formulaic approaches. This is perceptible in seemingly contradictory comments, such as, a feeling that, A-Level criteria allows a lot of freedom for students and teachers and perhaps even that 'A-level has much more potential to be like what foundation used to be' (IN9, FG3). In contradistinction to the feeling that teachers of A-level were unable or unwilling or not confident enough to embrace this perceived freedom. They were thought to be, 'teaching to a model of art that doesn't exist anywhere else in the world' (IN8, FG2). The comment reflects the peculiarity of the genre 'school-art' referred to earlier.

Many teachers of A-Level art are only too aware that they are teaching or being strongly encouraged to teach what I have referred to as a cynical curriculum (Robins 2003), and what Shepherd described as 'a kind of corrosion of what one knows to be true ... that undermines personal integrity'. As one of the focus group teachers remarked, 'I find it 
really upsetting, because it's not art actually, I don't believe it's art, I just think it's art skills. If they want us to teach art skills then that's how to do it, but it's not art.' (IN1, FG1)

The community who have experienced external assessment most forcefully applied are art educators working in secondary schools. For this sector morale and job satisfaction is currently low (NSEAD 2016, 40). School teachers recognise, as this interviewee confirms, that 'there is not enough joined up thinking between us and higher education, ...they, I mean higher education, well it doesn't feel like we are providing them with the students who can cope or who have had the right experiences' (IN15, FG4). 'It seems to me like the A-level that the exam boards have created serves such a different purpose from what happens next, you know, it's not preparing them [students] for the future' (IN13, FG5). These comment were made with a full awareness that it could be possible to do things differently. However, for that to happen there would need to be a radically transparent moderation system of A-level, which facilitates a supportive critical relationship not just between external moderators and heads of art but one that also opens up a dialogue and constructive, supportive relationships with the higher education sector. 


\section{References}

Ball, S. (2005) Education Policy and Social Class: The Selected Works of Stephen J. Ball. London and New York: Routledge.

Bourdieu, P. (1993) But Who Created the 'Creators'?, in Sociology in Question. London: Sage.

De La Harpe, B. and Peterson, F. (2008) A model for holistic studio assessment in the creative disciplines, Conference proceedings at 2008 ATN Assessment Conference. Available at: http://www.ojs.unisa.edu.au/index.php/atna/article/download/339/238 (accessed 4 September 2014).

Gielen, P. (2015) Lessons in Disproportion: The Role of Play in Arts Education and the Role of Art in Education. In: B. van Heusden and P. Gielen (eds) Art Education Beyond Art: Teaching Art in Times of Change. Amsterdam: Valiz.

Hughes, A, (1998) Reconceptualising the Art Curriculum, International Journal of Art and Design Education, 17 (1): 41-9.

Hughes, G. (2014) Ipsative Assessment: Motivation through marking progress. Basingstoke: Palgrave Macmillan.

Mason, R., Steers, J., Bedford, D. and McCabe, C. (2005) The impact of formal assessment on secondary school Art and Design education: a systematic description of 
empirical studies. In: Research Evidence in Education Library. London: EPPI-Centre, Social Science Research Unit, Institute of Education, University of London.

National Society for Education in Art and Design Survey Report 2015-16, 9 February 2016. Available at: http://www.nsead.org/downloads/survey.pdf (accessed 4 February 2016).

Orr, S. (2010) Making Marks assessment practices in art and design. Available at: http://www.adm.heacademy.ac.uk/resources/features/making-marks-assessementpractices-in-art-and-design/ (accessed 4 February 2016).

Robins, C. (2003) 'In and out of place - cleansing rites in art education'. In: N. Addison and L. Burgess (eds) Issues in art and design teaching. London: Routledge Falmer.

Robins, C., Hughes, G. and Craik-Horan, M. (2014) Pre-degree Summative Assessment in Art, Design and Media Study Full research report. London: University of the Arts London.

Schneider, B. (2012) Autonomy in Conservative Times, Art \& Education e-Journal. Available at: http://www.artandeducation.net/paper/autonomy-in-conservative-times/ (accessed 4 September 2014).

Slade School of Fine Art (2016) Available at: http://www.ucl.ac.uk/slade/degrees/ba-

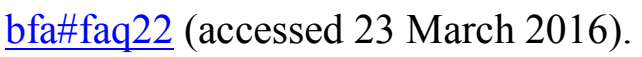


Smith, K. M. (2013) Assessment as a Barrier in Developing Design Expertise, International Journal of Art \& Design Education, 32 (2), 203-214, June 2013.

Shepherd, C. (2016) Supercalifragilisticexpialidocious: making sense of assessment in art and design. Unpublished MA assignment UCL IoE.

Stecher, B. (2010) Performance Assessment in an Era of Standards-Based Educational Accountability. Stanford, CA: Stanford University, Stanford Center for Opportunity Policy in Education.

Wenger, E. (1998) Communities of practice: learning, meaning and identity. Cambridge, Cambridge University Press. 


\section{Endnotes}

i The Universities and Colleges Admissions Service (UCAS) is a UK-based organisation that operates the application process for British universities.

ii Academy schools were introduced in England at the start of the twenty-first century. They are funded directly by the state, thereby circumventing local authority control. The rationale was to improve academic standards in 'failing schools' by encouraging them to be managed more like a private business with examination results constituting the measure of their success. They have been very controversial and debate continues regarding their effectiveness and or the damage they may have done.

iii Referring to the writing of Franz Kafka in which one experiences bureaucratic, senseless, disorientating and often menacing complexity. 